\title{
Challenges and future perspective for dengue vector control in the Western Pacific Region
}

\author{
Moh Seng Chang, ${ }^{a}$ Eva Maria Christophel, , Deyer Gopinath, ${ }^{b}$ and Rashid Md. Abdurc on behalf of Malaria, \\ Other Vectorborne and Parasitic Diseases, World Health Organization Regional Office for the Western Pacific \\ Correspondence to Moh Seng Chang (e-mail: changm@wpro.who.int)
}

Dengue remains a significant public health issue in the Western Pacific Region. In the absence of a vaccine, vector control is the mainstay for dengue prevention and control. In this paper we describe vector surveillance and vector control in the Western Pacific countries and areas.

Vector surveillance and control strategies used by countries and areas of the Western Pacific Region vary. Vector control strategies include chemical, biological and environmental management that mainly target larval breeding sites. The use of insecticides targeting larvae and adult mosquitoes remains the mainstay of vector control programmes.

Existing vector control tools have several limitations in terms of cost, delivery and long-term sustainability. However, there are several new innovative tools in the pipeline. These include Release of Insects Carrying a Dominant Lethal system and Wolbachia, an endosymbiotic bacterium, to inhibit dengue virus in the vector. In addition, the use of biological control such as larvivorous fish in combination with community participation has potential to be scaled up.

Any vector control strategy should be selected based on evidence and appropriateness for the entomological and epidemiological setting and carried out in both inter-epidemic and epidemic periods. Community participation and interagency collaboration are required for effective and sustainable dengue prevention and control. Countries and areas are now moving towards integrated vector management.

\section{BACKGROUND}

Dengue fever (DF) and dengue haemorrhagic fever (DHF) are on the increase in Asia and the Pacific. Countries and areas in the World Health Organization (WHO) Western Pacific Region are reporting more cases and an increase in the frequency of epidemics. Four countries in particular, Cambodia, Malaysia, the Philippines and Viet Nam (mainly southern Viet Nam), are facing annual epidemics that constitute over $90 \%$ of the total dengue cases reported in the Region. ${ }^{1}$

Given the lack of a dengue vaccine, control of dengue depends on vector control. Vector control is best achieved through management of breeding sites. The primary goal of vector control activities is to reduce vector population density to levels that are believed to correlate with a lower dengue transmission risk. ${ }^{2}$ The most important dengue vector in the Western Pacific Region is Aedes aegypti (Stegomyia aegypti), which is predominately found in densely populated urban areas. Dengue outbreaks have also been associated with Aedes albopictus, particularly in China, ${ }^{3}$ and several other
Aedes species found in South Pacific countries and areas may also be competent dengue vectors. ${ }^{4}$ Aedes breeding tends to occur in household containers.

In this paper we describe dengue vector surveillance and control practices in the Western Pacific Region and provide a perspective for future dengue control.

\section{DENGUE VECTOR SURVEILLANCE}

While insufficient to accurately predict the risk of human infection, dengue vector surveillance employs several entomological indicators that have been developed to assess the risk of outbreaks occurring. These include house index, Breteau index, container index and ovitrap indexes that are solely based on entomological parameters and lack epidemiological input. Models have attempted to redress this shortfall, including use of a pupal index that has been shown to be correlated to dengue seroprevalence in a population. ${ }^{5,6}$ A model employing all three parameters of dengue transmission - vector density, human cases and vector infection rate - would probably be the most accurate

\footnotetext{
a Malaria, Other Vectorborne and Parasitic Diseases, World Health Organization Regional Office for the Western Pacific, Manila, the Philippines

${ }^{b}$ Malaria, Other Vectorborne and Parasitic Diseases, World Health Organization, the Lao People's Democratic Republic

cMalaria, Other Vectorborne and Parasitic Diseases, World Health Organization, Cambodia

Submission date: 18 February 2011 ; Publication date: 30 June 2011

doi: 10.5365/wpsar.2010.1.1.012
} 
Table 1. Description of dengue vector surveillance in selected countries and areas of the Western Pacific Region

\begin{tabular}{|c|c|c|c|c|}
\hline $\begin{array}{l}\text { Selected countryl } \\
\text { area }\end{array}$ & Vector surveillance description & $\begin{array}{c}\text { Types of Aedes indices } \\
\text { used }\end{array}$ & Geographical areas & Frequency \\
\hline $\begin{array}{l}\text { Australia } \\
\text { (North } \\
\text { Queensland) } \\
\text { Australia } \\
\text { (Northern } \\
\text { Territory) }\end{array}$ & $\begin{array}{l}\text { - BG-Sentinel }{ }^{\mathrm{TM}} \text { or BG traps and net } \\
\text { traps for adult vector monitoring } \\
\text { - Ovitraps (lethal traps) in sentinel } \\
\text { urban areas } \\
\text { - Larval surveys for presence of vectors } \\
\text { and to assess residual applications to } \\
\text { receptacles } \\
\text { - Larval surveys, standard ovitraps, BG } \\
\text { and Encephalitis Vector Survey traps } \\
\text { for vector importation presence }\end{array}$ & $\begin{array}{l}\text { House and Breteau } \\
\text { Adult BG trap presence } \\
\text { only (vector free but } \\
\text { frequent importations) }\end{array}$ & $\begin{array}{l}\text { Selected sites in sentinel } \\
\text { urban areas and port } \\
\text { areas } \\
\text { Principal overseas port } \\
\text { areas, selected urban } \\
\text { sentinel sites }\end{array}$ & $\begin{array}{l}\text { Regular /monthly } \\
\text { during summer } \\
\text { rainy season and } \\
\text { outbreaks } \\
\text { Weekly to } \\
\text { fortnightly }\end{array}$ \\
\hline Cambodia & $\begin{array}{l}\text { Larval/pupal surveys in sentinel } \\
\text { surveillance sites to assess high-risk } \\
\text { areas and mass larvicide control } \\
\text { measures }\end{array}$ & $\begin{array}{l}\text { House, Breteau, } \\
\text { container and pupal } \\
\text { density }\end{array}$ & $\begin{array}{l}\text { Sentinel sites in urban, } \\
\text { semi-urban and rural } \\
\text { areas }\end{array}$ & $\begin{array}{l}\text { Not regular } \\
\text { Rainy and dry } \\
\text { seasons }\end{array}$ \\
\hline China & $\begin{array}{l}\text { - Human landing catch } \\
\text { - Light trap and net trap for vector } \\
\text { monitoring }\end{array}$ & $\begin{array}{l}\text { House, Breteau, } \\
\text { container and pupal } \\
\text { density }\end{array}$ & $\begin{array}{l}\text { Selected sites in urban } \\
\text { and semi-urban areas }\end{array}$ & $\begin{array}{l}\text { Not regular } \\
\text { As study projects }\end{array}$ \\
\hline $\begin{array}{l}\text { Hong Kong } \\
\text { (China) }\end{array}$ & $\begin{array}{l}\text { Routine ovitrap surveillance in } \\
\text { sentinel sites to monitor vector density } \\
\text { and generate ovitrap index as dengue } \\
\text { risk indicator }\end{array}$ & Ovitrap & $\begin{array}{l}\text { Sentinel sites in urban } \\
\text { residential areas }\end{array}$ & $\begin{array}{l}\text { Regular, throughout } \\
\text { the year }\end{array}$ \\
\hline $\begin{array}{l}\text { Lao People's } \\
\text { Democratic } \\
\text { Republic }\end{array}$ & $\begin{array}{l}\text { Sentinel surveillance sites to assess } \\
\text { high-risk areas and community } \\
\text { participation }\end{array}$ & $\begin{array}{l}\text { House, Breteau and } \\
\text { container }\end{array}$ & $\begin{array}{l}\text { Sentinel sites in urban, } \\
\text { semi-urban and rural } \\
\text { areas }\end{array}$ & Not regular \\
\hline Malaysia & $\begin{array}{l}\text { Larval surveys to assess the density } \\
\text { of vector breeding sites and high risk } \\
\text { areas } \\
\text { - Ovitrap surveys as research projects } \\
\text { - Surveys as part of epidemic response } \\
\text { activities for law enforcement }\end{array}$ & $\begin{array}{l}\text { House, Breteau and } \\
\text { container }\end{array}$ & $\begin{array}{l}\text { Urban, suburban and } \\
\text { nationwide }\end{array}$ & Routine \\
\hline Philippines & $\begin{array}{l}\text { - Larval/pupal surveys in selected sites } \\
\text { for community-based vector control } \\
\text { - Vector surveys as part of } \\
\text { entomological research activities }\end{array}$ & $\begin{array}{l}\text { House, Breteau, } \\
\text { container and pupal } \\
\text { density }\end{array}$ & Urban, suburban & Not regular \\
\hline Singapore & $\begin{array}{l}\text { - Larval surveys to assess the } \\
\text { presence of vector, vector activity and } \\
\text { distribution, and to monitor breeding } \\
\text { habitats } \\
\text { - Ovitrap to assess the effectiveness of } \\
\text { control measures and to monitor } \\
\text { high-risk areas }\end{array}$ & $\begin{array}{l}\text { House, Breteau, } \\
\text { container and ovitrap }\end{array}$ & $\begin{array}{l}\text { Urban, suburban and } \\
\text { nationwide }\end{array}$ & Routine \\
\hline Viet Nam & $\begin{array}{l}\text { Sentinel surveillance sites to assess } \\
\text { high-risk areas and community-based } \\
\text { vector control }\end{array}$ & $\begin{array}{l}\text { House, Breteau, } \\
\text { container and pupal } \\
\text { density }\end{array}$ & $\begin{array}{l}\text { Sentinel sites in urban, } \\
\text { semi-urban and rural } \\
\text { areas }\end{array}$ & Not regular \\
\hline
\end{tabular}

in determining outbreak thresholds for early outbreak prediction. Vector surveillance is conducted using these and other indicators in several Western Pacific Region countries and areas (Table 1).

\section{DENGUE VECTOR CONTROLSTRATEGIES}

Vector control methods and strategies differ across countries and areas in the Western Pacific Region (Table 2). Strategies depend upon specific dengue vector ecology, case burden, availability of resources, feasibility of proper application and the cultural context of the country. An understanding of local mosquito ecology is important for determining an effective, targeted strategy. The trend for dengue vector control in the Region has shifted from relying solely on insecticides to include source reduction, biological control and environmental management through community participation. However, insecticide use is still the mainstay of dengue vector control during outbreaks. 
Table 2. Control of dengue virus vectors (Aedes aegypti and Aedes albopictus) in Western Pacific Region

\begin{tabular}{|c|c|c|c|c|c|c|c|}
\hline Countrylareas & $\begin{array}{c}\text { Space } \\
\text { spraying } \\
\text { (outbreak) }\end{array}$ & $\begin{array}{c}\text { Larviciding } \\
\text { (chemical \& } \\
\text { biological } \\
\text { larvicide) }\end{array}$ & $\begin{array}{l}\text { Biological } \\
\text { control }\end{array}$ & $\begin{array}{c}\text { Environmental } \\
\text { management } \\
\text { (source } \\
\text { reduction) }\end{array}$ & $\begin{array}{l}\text { Health } \\
\text { education and } \\
\text { community } \\
\text { mobilization) }\end{array}$ & Legislation & $\begin{array}{l}\text { Intersectoral } \\
\text { and agency } \\
\text { collaboration }\end{array}$ \\
\hline $\begin{array}{l}\text { Australia } \\
\text { (North Queensland }\end{array}$ & ++ & ++ & & ++ & ++ & + & + \\
\hline $\begin{array}{l}\text { Australia } \\
\text { (Northern Territory }\end{array}$ & ++ & ++ & & ++ & ++ & & \\
\hline Cambodia & + & ++ & $\begin{array}{l}+ \text { (guppy fish } \\
\text { as operational } \\
\text { research) }\end{array}$ & + & $\begin{array}{l}+ \text { (school } \\
\text { based })\end{array}$ & - & + \\
\hline China & + & - & - & + & + & - & + \\
\hline $\begin{array}{l}\text { Hong Kong (China) \& } \\
\text { Macau (China) }\end{array}$ & + & - & - & + & + & + & + \\
\hline $\begin{array}{l}\text { Lao People's } \\
\text { Democratic Republic }\end{array}$ & + & + & $\begin{array}{l}+ \text { (guppy fish } \\
\text { as operational } \\
\text { research) }\end{array}$ & + & ++ & - & + \\
\hline Fiji & + & + & - & + & + & - & - \\
\hline Malaysia & + & + & - & + & + & ++ & + \\
\hline Philippines & + & + & $\begin{array}{l}+ \text { (guppy fish } \\
\text { as operational } \\
\text { research) }\end{array}$ & + & + & - & + \\
\hline Solomon Islands & + & - & - & - & + & - & - \\
\hline Singapore & + & + & - & + & + & ++ & ++ \\
\hline Vanuatu & + & + & - & + & + & - & + \\
\hline Viet Nam & + & + & + (Mesocyclops) & + & ++ & + & + \\
\hline
\end{tabular}

A systematic literature review and case studies describing dengue vector control services by the WHO Special Programme for Research and Training in Tropical Diseases have been published elsewhere. ${ }^{7}$ The following review provides information on national dengue control operational strategies implemented at the programmatic level.

\section{(1) Chemical treatment of breeding sites}

Larvicides to prevent vector breeding are used in several countries and areas in the Western Pacific Region. In Cambodia, timely larviciding before the dengue season in targeted, densely populated areas has been designed as a short-term intervention since 2000. The intervention was reported to have reduced the number of dengue cases and deaths by $53 \%{ }^{8}$ Targeted containers in stratified dengue high risk areas are treated twice annually to prevent outbreaks. Large containers can also be specifically targeted, both as a preventive method and during outbreaks. ${ }^{8}$
Application to every possible breeding container in the Greater Mekong Subregion countries is not feasible due to cost and operational delivery shortfalls. Larvicides should be used in tandem with community mobilization and environmental management. Larvicides furthermore carry the risk of development of insecticide resistance and community dependence on expensive, centrally planned interventions. Wide-scale outbreaks in Cambodia in 2007, outside the stratified high-risk areas, and presence of abundant discarded containers and cryptic breeding sites underline the possibility of dengue spreading into new rural areas where the control programme cannot easily use larvicides for outbreak mitigation and prevention.

During outbreaks, chemical larvicides are used to target containers breeding vectors in houses near case clusters. While larviciding is effective at lowering vector density, infectious adult mosquitoes are not affected and transmission may continue for the remaining 
lifetime of the infectious adult mosquito. In Australia (North Queensland) a residual insect growth regulator (methoprene) is regularly used in discarded and disused containers, roof gutters, rainwater tanks and other rainwater-collecting containers to reduce overall populations seasonally and for outbreak control. ${ }^{9}$

The World Health Organization Pesticide Evaluation Scheme recommends several larvicides including temephos, insect growth regulators and Bacillus thuringiensis that are safe for drinking-water treatment. ${ }^{10}$ There are reports from Malaysia on the high efficacy of Bacillus thuringiensis var. israelensis, distributed by space spraying for vector control. ${ }^{11,12}$

\section{(2) Insecticide spraying}

Chemical insecticide spraying is designed to reduce disease transmission by lowering the adult vector population and targeting infectious adults through reducing their longevity. The writers are of the opinion that spraying is recommended only as a method of controlling ongoing or preventing incipient outbreaks through a single, massive reduction in adult vector density. However the practice of indiscriminate or widescale outdoor spraying is of questionable effectiveness since many mosquitoes may be inaccessible and would be unaffected. In addition, the insecticidal effects of spraying are transient and depend on persistence of the insecticide used and method of application.

A long timelag between reporting of human cases and commencement of spraying also minimizes the effects of intervention. This lag is likely longest in resource-constrained countries with rural populations where reporting of cases and commencement of vector control activities take longest. Clinicians at lower levels of the health systems may not recognize dengue symptoms, and the surveillance system in rural areas may be relatively poor. In these situations, spraying operations will take longer to implement. Poor functionality of sprayers, insufficient coverage of spraying and incorrect dosage of chemical insecticides coupled with poor public acceptance and compliance also affect the effectiveness of operations. While local teams should have the expertise to conduct spraying effectively, central-level Ministry of Health staff may be required to supervise to ensure the quality of operations.

\section{(3) Biological control}

Biological control of dengue vectors is based on the concept of introducing organisms that prey upon, compete with, or otherwise reduce the density of vectors. In the case of Aedes aegypti, the immature stages of the vectors in household water containers provide a suitable target for the introduction of biological control agents. Their introduction must be safe, inexpensive, easy to produce on a large scale and be culturally and socially acceptable to the target population. In the case of Aedes mosquitoes, certain species of fish and predatory copepods have proven effective. ${ }^{13-15}$

Viet Nam has experimented with the use of the copepod Mesocyclops as a community-based biological control agent. ${ }^{13,14}$ The project yielded promising results, and within three years less than $1.5 \%$ of houses were positive for dengue vectors in the project areas. This successful model was due to a combination of vertical and horizontal approaches, identification of key Aedes breeding sites and strong multisectoral cooperation. When used in combination with community source reduction, the use of Mesocyclops is an easy and inexpensive method of Aedes aegypti control that should be effective for many communities in Viet $\mathrm{Nam}$ and elsewhere. ${ }^{13}$

In Cambodia, a successful trial of the effectiveness of introducing larvivorous guppy fish (Poecilia reticulata) into water storage containers has taken place in a single commune. The trial was successful, with households receiving the intervention exhibiting a $79.0 \%$ reduction in Aedes container index compared with control houses. ${ }^{15}$ This trial used community volunteers to colonize and distribute guppies and showed a clear impact on entomological indices in the 14-village trial area. Communities were enthusiastic regarding the intervention which offers greater convenience than emptying/washing containers, and only two to three guppy fish are required to control mosquito and plankton/ algal growth in each 200-400 litre water container. To assess the effectiveness of the intervention on a larger scale, a communication for behavioural impact ${ }^{16}$ (COMBI) project advocating the use of guppies in tandem with source reduction is currently being implemented in districts of Cambodia and the Lao People's Democratic Republic. ${ }^{17}$

\section{(4) Environmental management and vector control}

In some areas of the Greater Mekong Subregion, over $80 \%$ of households harbour breeding dengue vectors, largely as a result of water storage practices. ${ }^{17}$ Households often feature water storage containers kept outside. These containers, used to store rain, river or well 
water for household use and drinking-water for animals are extremely difficult to protect from Aedes aegypti infestation. In addition, discarded containers, tyres and other vessels collect rainwater during the rainy season, providing excellent Aedes aegypti breeding sites. In some countries and areas, water storage containers are scarce and breeding sites are more difficult to locate. In Macau (China), for example, key breeding sites of Aedes albopictus larvae and pupae include water collection wells of closed underground drains, lotus flower jars, garden stone pools and fountains. In Malaysia, breeding sites are often discarded and neglected containers rather than domestic water storage containers. Other potential breeding sites are containers found in parks, empty land, industry buildings, construction sites, and blocked cement drains and septic tanks. Vector control should be targeted to key breeding sites as identified from vector surveillance.

Environmental management aims to alter the environment to minimize vector breeding sites, especially in close proximity with humans, and therefore minimize human-vector contact. These modifications may be longlasting measures and include modifying building designs such as roof gutters to prevent Aedes breeding, ${ }^{18}$ installing flip type water tank covers to deny gravid female Aedes entry and repairing blocked cement drains. Shortterm environmental modification measures involve local agencies and engagement of the community. General household sanitation is key to preventing Aedes breeding in domestic environments, and the local authority's role is to ensure no accumulation of water containers in public places.

\section{(5) Community mobilization}

Community-based dengue vector control using $\mathrm{COMBI}$ as a planning tool is being incorporated into dengue control programmes in Malaysia, the Lao People's Democratic Republic and the Philippines. Since 2007, the Lao People's Democratic Republic Women's Union has been involved in community mobilization for dengue awareness and larvae detection in households in provinces. It is also involved in distribution of larvicide for dengue outbreak intervention. Community mobilization and school-based dengue control activities have been also piloted. ${ }^{19}$

Similar approaches have already been shown to be effective in Singapore through intensified community action using simple dengue prevention messages through community outreach teams. After a
2005 outbreak, Singapore intensified community dengue prevention adopting "10-Minute Mozzie Wipeout" using simple dengue prevention messages targeting residents, construction workers, factory workers and foreign maids. Community engagement also takes place using dengue volunteers delivering dengue prevention messages in the community. ${ }^{18}$

While COMBI projects, adapted from the field of marketing, have the potential to make a sustained impact on dengue vector density, there has been little evidence of the impact of COMBI interventions on dengue transmission or outbreak prevention. Projects implemented in the Region have lacked sufficient evaluation of the sustainability of behavioural changes or the impact on vector control and dengue transmission. Despite advocacy of community participation and mobilization, communities may be reluctant to take appropriate dengue preventive measures except during outbreaks when the effects of dengue are clearest. In the Greater Mekong Subregion, reports of weekly washing of large water storage containers may not reflect actual community practice. Frequent washing of these large containers is not practical, particularly when they are full of scarce water and are in frequent daily use. COMBI processes should be used to effectively communicate and deliver proven tools for dengue prevention. One of the objectives of the current guppy fish project in Cambodia and the Lao People's Democratic Republic is to identify a community-based dengue vector control tool and use the COMBI process to deliver this tool in the community and thus achieve behavioural change. In this case, a key behavioural change message has been "inspect your water containers for guppy fish on a weekly basis."

\section{INTERAGENCY COLLABORATION FOR DENGUE CONTROL IN THE REGION}

The WHO Asia-Pacific Dengue Strategic Plan (20082015) consists of six components; two of these related to vector control are integrated vector management (IVM) and social mobilization and communication. ${ }^{20}$ These dengue control activities require interagency collaboration and partnership with other agencies in promoting community-based dengue control. Many countries and areas of the Western Pacific Region use this approach.

Dengue control activities in cities and townships in Malaysia are the responsibility of local authorities. ${ }^{21}$ The Minister of Local Government and Housing has equal responsibility with the Ministry of Health for dengue 
control. Other agencies involved in dengue prevention and control are the Ministry of Education, Ministry of Environment, Judicial Department and community organization groups. The Ministry of Agriculture is the pesticide regulatory agency. However, there is also a pesticide board responsible for pesticide registration and monitoring use. Most recently, the Ministry of Health is adapting $\mathrm{COMBI}$ planning tools aimed at behavioural change in several states in Peninsular Malaysia.

In Singapore, the National Environment Agency (NEA) is the main agency for dengue vector control while cases are reported from the Ministry of Health. When mounting search, destroy and fogging operations, the NEA also alerts residents and involves the community to remove breeding habitats from homes. Private pest management operators, land agencies and town councils also coordinate with the NEA to maintain close surveillance and carry out intensive mosquito treatment especially in endemic areas. ${ }^{18}$ For community-based activities, the NEA works in partnership with Community Development Councils and construction firms to curb Aedes mosquito breeding at homes and construction sites.

In Australia, Queensland Health has formulated a Dengue Fever Management Plan for North Queensland where Ae. aegypti is widespread. The plan focuses on disease surveillance, mosquito control and surveillance and education. Mosquito control is managed by a special unit of Queensland Health, the Dengue Action Response Team (DART). DART operates under the Queensland Public Health Act 2005 that allows the right of access to all yards (excluding houses) to set lethal ovitraps and apply pesticides to any container with mosquitoes. ${ }^{9}$

In 2002, the Fifty-fifth World Health Assembly adopted resolution WHA55.17 which addressed dengue and dengue haemorrhagic fever prevention and control, ${ }^{22}$ thereby creating a political environment supportive of international, regional and national dengue activities. In response to this resolution, the Government of Cambodia worked in collaboration with international and bilateral agencies to strengthen the surveillance capacity of the National Dengue Control Programme, to intensify training on clinical management of dengue haemorrhagic fever and to develop, finance and begin implementation of a five-year vector control plan from 2001. A national dengue control committee was set up and established at Ministry level to plan, coordinate and implement the national strategy. Based on vector ecology, dengue endemicity and the socioeconomic situation in Cambodia, the programme focused on lowering epidemic potential through timely application of larvicide via mobilization of thousands of citizens, including local authorities, community volunteer networks and Red Cross workers. In collaboration with the Ministry of Education, School Health Department, a school-based dengue control pilot project was launched in 2005. Several community-based vector control projects have also been implemented and are undergoing field trials, including community use of insecticidal impregnated jar covers, integrated vector control using guppy fish and source reduction activities. ${ }^{23}$

\section{FUTURE PERSPECTIVE}

Despite recent heightened awareness for dengue prevention, various challenges still exist. These include inadequate funding and resources and the lack of a sound strategy to respond to the increasing problem of dengue outbreaks in a growing number of geographical areas. Rapid urbanization, lack of basic sanitation, increased mobility of populations and international travel has compounded the problem in some countries and areas, and there is no promising solution for sustainable control of dengue vectors. Given the complexity of dengue vector control at national level, a well-organized dengue control programme should be established to collaborate with different sectors, ministries, agencies and partners to plan, implement and facilitate these activities.

For vector control, there is a need for increased capacity in outbreak response as a component of a three-pronged strategy. This strategy should include community-based larvae control (using environmental management and other technologies as appropriate), adult mosquito management (including research into novel insecticides and their application) and use of personal protection (including research on repellents, adult reduction devices and their mode of delivery).

Preventive activities should be built into existing health care systems and be well coordinated within primary health care activities rather than within the dengue control programme of Ministries of Health. WHO is advocating Integrated Vector Management (IVM) as a further method of dengue vector control. ${ }^{24}$ IVM is defined as "a rational decision-making process for the optimal use of resources for vector control." The important attributes of IVM are advocacy, social mobilization and legislation, collaboration within the 
health sector and with other sectors, an integrated intervention methods approach, evidence-based decision-making and capacity-building. ${ }^{25}$ IVM is suited to dengue management and control programmes in dengue endemic countries and should be used when planning dengue prevention in the Region. To improve the efficiency and effectiveness of dengue vector control, increasing the capacity of countries to implement IVM is critical. The basic elements of dengue control under IVM are to adopt evidence-based selection and delivery of different interventions (or combinations of interventions) based on local settings to increase country vector control delivery capacity in all geographical areas and to implement monitoring and evaluation tools.

New vector control tools for Aedes aegypti population suppression and replacement are currently under investigation. The use of Sterile Insect Technique is not a new approach, and it has been used for insect population control against a wide range of agriculture pest insect species. ${ }^{26}$ The recently developed Release of Insects Carrying a Dominant Lethal (RIDL) system incorporates a novel genetic sexing system for mass rearing of male mosquitoes. ${ }^{27}$ Under this new technology, a lethal gene was micro-injected into the eggs of Aedes aegypti. The gene subsequently integrated into the genome of the mosquito. The gene regulates the production of toxic metabolites in the larval stage, killing the larva. The antibiotic tetracycline is used to rear larvae and to maintain the mosquito in the laboratory. This antibiotic inhibits the lethal gene and produces no toxin, allowing larvae to develop fully into adults. In actual control, RIDL males will be released to mate with wild females. Fertilized females will produce eggs that hatch into larvae carrying the RIDL gene. All those carrying the gene will die at late larval or early pupal stage. The Malaysia Institute for Medical Research (IMR) has conducted this project in three phases: (1) establishment of the transgenic Malaysian strain of Aedes aegypti; (2) simulation release trial inside a field house; and (3) field release in a suitable experimental field site. Currently IMR is implementing the third phase.

Another development in terms of novel vector control is the discovery that the naturally occurring endosymbiotic bacterium Wolbachia - commonly present in insect populations - can inhibit replication of the dengue virus in Aedes aegypti mosquitoes. ${ }^{28}$ The idea is to introduce these strains of Wolbachia into wild populations of Aedes aegypti, potentially replacing field populations in a way that could suppress or even possibly eliminate dengue transmission.

Vector surveillance must also be improved, including data on key and target container types for better breeding site management. A geographic information system (GIS)-based approach to dengue control and surveillance can link relevant spatial data to identify key patterns and relationships, aiding in planning and strategic decisionmaking. ${ }^{29}$ Thematic maps can be produced to visualize the spatial distribution of dengue vectors in relation to relevant environmental and climatic indicators. Similarly, dengue cases and vector densities can be mapped to view the spatial patterns of dengue distribution over time and to monitor potential movements of dengue transmission foci after outbreaks have been identified. Through the combination and integration of detailed spatial information into a centralized GIS database, programme managers will be equipped with a simple yet powerful decision-making, planning, surveillance and community education tool for dengue management.

\section{CONCLUSIONS}

Although intense efforts are under way to develop a vaccine, there is neither vaccine to prevent dengue nor are there any effective antiviral drugs to treat the disease. To minimize the impact of dengue outbreaks, countries and areas should strengthen their vector control programmes, both during inter-epidemic and epidemic periods. Control strategies should use integrated approaches with evidence-based selection and delivery of different interventions or combinations of interventions adapted to different entomological and epidemiological settings. Dengue prevention and control should include individuals, families and the wider community and encourage community participation to have the best chances of success.

\section{Conflict of interest}

None declared.

\section{Funding}

This study was undertaken as part of routine activities of the WHO Western Pacific Regional Office.

\section{References:}

1. Dengue in the Western Pacific Region (cited 2000-2009). Manila, World Health Organization for the Western Pacific Region (http://www.wpro.who.int/topics/dengue/en, accessed on 10 June 2011). 
2. Eisen $L$ et al. Proactive vector control strategies and improved monitoring and evaluation practices for dengue prevention. Journal of Medical Entomology, 2009, 46:1245-1255. doi:10.1603/033.046.0601 pmid:19960667

3. Wu JY et al. Dengue fever in mainland China. The American Journal of Tropical Medicine and Hygiene, 2010, 83:664-671. doi:10.4269/ajtmh.2010.09-0755 pmid:20810836

4. Belkin JN. Mosquitoes of the South Pacific (Diptera, Culicidae). Berkeley, University of California Press, 1962.

5. Focks DA. A review of entomological sampling methods and indicators for dengue vectors. Geneva, World Health Organization on behalf of the Special Programme for Research and Training in Tropical Diseases, 2003 (http://www.who.int/tdr/publications/ documents/dengue vectors.pdf, accessed on 18 May 2011).

6. Focks DA, Alexander N. Multicountry study of Aedes aegypti pupal productivity survey methodology: findings and recommendations. Geneva, World Health Organization on behalf of the Special Programme for Research and Training in Tropical Diseases, 2006 (http://www.who.int/tdr/publications/documents/aedes aegypti. pdf, accessed on 18 May 2011).

7. Horstick $O$ et al. Dengue vector-control services: how do they work? A systematic literature review and country case studies. Transactions of the Royal Society of Tropical Medicine and Hygiene, 2010, 104: 379-386. doi:10.1016/j.trstmh.2009.07.027 pmid:20400169

8. Suaya JD et al. Cost-effectiveness of annual targeted larviciding campaigns in Cambodia against the dengue vector Aedes aegypti. Tropical Medicine \& International Health, 2007, 12: 1-11. pmid: 17207142

9. Ritchie SA. Evolution of dengue control strategies in North Queensland, Australia. Arborvirus Research in Australia, 2005, 9: 324-330 (http://www.mosquitoscience.net/pdfs/Ritchie-evolutiondengue-TPHU-ARA-05-ms.pdf, accessed on 18 May 2011).

10. Pesticides and their application for the control of vectors and pests of public health importance. Geneva, WHO Pesticide evaluation scheme: Department of Control of Neglected Tropical Diseases, 2006:31 (http://whqlibdoc.who.int/hq/2006/WHO CDS NTD WHOPES GCDPP 2006.1 eng.pdf, accessed on 18 May 2011)

11. Lam PHY et al. Aedes albopictus control with spray application of Bacillus thuringiensis israelensis, strain AM 65-52. The Southeast Asian Journal of Tropical Medicine and Public Health, 2010, 41:1071-1081. pmid:21073027

12. Lee $\mathrm{HL}$ et al. Impact of larviciding with a Bacillus thuringiensis israelensis formulation, VectoBac WG, on dengue mosquito vectors in a dengue endemic site in Selangor State, Malaysia. The Southeast Asian Journal of Tropical Medicine and Public Health, 2008, 39:601-609. pmid:19058596

13. Kay BH, Vu SN. New strategy against Aedes aegypti in Vietnam. Lancet, 2005, 365:613-617. pmid:15708107

14. Nam VS et al. National progress in dengue vector control in Vietnam: survey for Mesocyclops (Copepoda), Micronecta (Corixidae), and fish as biological control agents. The American Journal of Tropical Medicine and Hygiene, 2000, 62:5-10. pmid:10761718

15. Seng $\mathrm{CM}$ et al. Community-based use of the larvivorous fish Poecilia reticulata to control the dengue vector Aedes aegypti in domestic water storage containers in rural Cambodia. Journal of Vector Ecology, 2008, 33:139-144. doi:10.3376/10811710(2008)33[139:CUOTLF]2.0.CO;2 pmid:18697316

16. Parks W, Lloyd L. Planning social mobilization and communication for dengue fever prevention and control - a step-by-step guide.
Geneva, World Health Organization, 2004 (http://whqlibdoc. who.int/publications/2004/9241591072.pdf, accessed on 18 May 2011).

17. Beaver C, Palmer KTA. No. 7268-REG: Regional Public Goods for Health: Combating Dengue in ASEAN Inception Report. Manila, Asian Development Bank, 2010 (http://gms-cdc.org/resource/doc view/788-inception-report-28-feb-2010.raw?tmpl=component, accessed on 10 June 2011).

18. Ng LC. Singapore's dengue control programme in the face of new challenges. In: Asia-Pacific dengue programme managers meeting 5 to 9 May 2008, Singapore. Manila, World Health Organization Western Pacific Regional Office, 2008:33-39.

19. Chang MS. Dengue in the Greater Mekong Sub-region: status, epidemiology and control. Report presented in the GMS public health forum, 5-7 November 2007, Vientiane, The Lao People's Democratic Republic.

20. The dengue strategic plan for the Asia Pacific Region 2008-2015 Manila, World Health Organization South-East Asia Region and Western Pacific Region, 2005 (http://www.wpro.who.int/internet/ resources.ashx/MVP/Dengue+Strategic+Plan.pdf, accessed on 18 May 2011).

21. Yusoff HM. National dengue programme in Malaysia. In: AsiaPacific dengue programme managers meeting, 3-9 May 2008, Singapore. Manila, World Health Organization Western Pacific Regional Office, 2008, 83-86 (http://www.wpro.who.int/internet/ files/mvp/Dengue_Report.pdf, accessed on 19 May 2011).

22. Resolution WHA. 55.17 Agenda item 13.14 Dengue fever and Dengue haemorrhagic fever prevention and control. Geneva, World Health Organization (http://www.who.int/neglected diseases/mediacentre/WHA_55.17_Eng.pdf, accessed on 10 June 2011).

23. Seng $\mathrm{CM}$ et al. The effect of long-lasting insecticidal water container covers on field populations of Aedes aegypti (L.) mosquitoes in Cambodia. Journal of Vector Ecology, 2008, 33:333-341. doi:10.3376/1081-1710-33.2.333 pmid:19263854

24. Global Strategic Framework for Integrated Vector Management. Geneva, World Health Organization, 2004 (http://whqlibdoc.who. int/hq/2004/WHO CDS CPE PVC 2004 10.pdf, accessed on 18 May 2011).

25. Report of the WHO Consultation on Integrated Vector Management (IVM), WHO Headquarters, Geneva, Switzerland, 1-4 May 2007. Geneva, World Health Organization, 2007 (http://www.searo.who. int/LinkFiles/Publications and Documents Report of the WHO consultation_on_IVM.pdf, accessed on 18 May 2011).

26. Krafsur E. Sterile insect technique for suppressing and eradicating insect populations: 55 years and counting. Journal of Agricultural Entomology, 1998, 15:303-317.

27. Alphey $L$ et al. Insect population suppression using engineered insects. In: Serap Aksoy, Landes Bioscience and Springer Science+Business Media eds. Transgenesis and the management of vector borne diseases. New York, Springer, 2008, 93104.

28. Jeffery JAL et al. Characterizing the Aedes aegypti population in a Vietnamese village in preparation for a Wolbachia-based mosquito control strategy to eliminate dengue. PLoS, 2009, 3:e1371 (http://www.eliminatedengue.com/Portals/58/PDFs/journal. pntd.0000552.pdf, accessed on 10 June 2011).

29. Eisen L, Lozano-Fuentes S. Use of mapping and spatial and spacetime modelling approaches in operational control of Aedes aegypti and Dengue. Plos Neglected Tropical Medicine, 2009, 3:e411. doi:10.1371/journal.pntd.0000411 pmcid:pmc2668799 